\title{
Stasis ulcer is a chronic condition of combined venous and lymphatic insufficiency: Phlebo-lymphedema (PLE)
}

\author{
BB Lee ${ }^{1}$ \\ ${ }^{1}$ Professor of Surgery and Director, Center for the Lymphedema and Vascular Malformations, George Washington \\ University, Washington DC, USA.
}

submitted: Dec 18, 2019, accepted: May 12, 2020, EPub Ahead of Print: May 24, 2020

Conflict of interest: None

DOI: 10.24019/jtavr.79 - Corresponding author:Prof. Byung Boong Lee, bblee38@comcast.net

(C) 2019 Fondazione Vasculab impresa sociale ONLUS. All rights reserved.

\begin{abstract}
Indolent venous stasis ulcers often represent a combined condition of veno-lymphatic edema caused by chronic venous insufficiency (CVI) and chronic lymphatic insufficiency (CLI) of various origins, known as phlebolymphedema (PLE). Primary PLE, caused by vascular malformation component of Klippel-Trenaunay syndrome, is the combined condition of CVI by the marginal vein (MV) and CLI by primary lymphedema. Primary PLE with CVI by the reflux of MV can be treated successfully with MV resection, Secondary PLE with CVI by the postthrombotic syndrome (PTS) can be further improved with correction of the venous outflow obstruction with angioplasty $\&$ stent.
\end{abstract}

Keywords chronic venous insufficiency, chronic lymphatic insufficiency, phlebolymphedema, marginal vein, primary lymphedema, angioplasty \& stent

\section{Definition: Hemodynamic aspect}

The Saint Peregrine's sore is the symbol of chronic venous stasis ulcer along the lower extremity. Indeed, these 'indolent' venous stasis ulcers on the distal lower leg has been a hall mark of 'advanced' chronic venous insufficiency (CVI) for many decades as the sequalae of the deep vein thrombosis (DVT) mainly affecting femoral-popliteal vein system, often known as post-thrombotic syndrome $(\mathrm{PTS})^{1-4}$.

Although these ulcers might have been started as a single venous condition solely caused by CVI at the beginning, the local condition will change to advance to a 'combined' condition of venous and lymphatic insufficiency when the ulcers should remain incalcitrant, resisting the healing. (e.g. secondary phlebolymphedema), so called 'Phlebo-lymphedema'(PLE) ${ }^{5-8}$.

Indeed, due to hemodynamically unique condition of venous-lymphatic circulation system as one 'inseparable' system, they are 'mutually interdependent' to transport the used blood out from the tissue although they function in entirely different rheodynamic conditions with different characteristics $^{9-12}$.

'Normal' lymphodynamic is based on self-propelled peristalsis by chains of multiple units of 'lymphangion' to coordinate contractility to reduce pressure downstream before additional fluid arrives from upstream segments and able to overcome a pressure gradient in excess of $30 \mathrm{mmHg}$ $(\sim 40 \mathrm{cmH} 2 \mathrm{O})$ in human legs ${ }^{13,16}$, while venodynamics is purely based on a passive low-pressure system of $10 \mathrm{mmHg}$ in average run by heart, diaphragm/breathing, and muscle contraction, etc. However, critical aspect of lymphodynamic is once this normal peristaltic function of lymphangion should be lost by various conditions, the 'abnormal' lymphodynamic becomes essentially same as the venodynamics.

Despite these two systems run based on totally different venodynamics and lymphodynamics, they are mutually dependent dual outflow system of the circulation so that the failure of one system gives additional burdening/ loading to the other system. And long term one system failure results in total failure of this 'inseparable' dual system altogether: phlebolymphedema ${ }^{13-16}$. 
Another word, venous and lymphatic systems are such one 'inseparable' system so that the insufficiency or overload of various etiologies, either transient or permanent, to one of two systems allows the other to play an auxiliary role of fluid return through micro- \& macro-anastomotosis. But, both systems are 'mutually complimentary' only when they are in normal function; when one of two systems should lose its normal function (eg. chronic venous hypertension, lymphedema), such mutual interdependence generates a new problem: phlebolymphedema.

Hence, phlebolymphedema is a combined condition of phlebogenic leg edema (=phlebo-edema) and lymphogenic leg edema (=lympho-edema) to be defined as 'lymphatico-venous edema' representing the accumulation of excess intercellular fluid in the legs and feet due to lymphatic obstruction/ failure as the result of $\mathrm{CVI}^{17-20}$.

When the CVI results in an excessive fluid load to the tissue level, it would disrupt check and balance function of the capillary system giving additional load to the lymphatic system. When this overloading exceeds the maximum capacity of normal lymphatic compensation, it results in chronic lymphatic insufficiency (CLI).

This CLI becomes more prominent especially among the 'compromised' lymphatic drainage condition of various etiologies (e.g. surgery/radiotherapy associated with cancer treatment). Clinical manifestation of the PLE is therefore, extremely variable depending upon the etiology (primary and secondary) and the degrees/extents of the CVI and CLI, and clinically more distinctive along the lower extremity.

The lymphedema secondary to CVI has been called 'phlebolymphedema' for the last two decades but more precisely, phlebolymphedema can be defined to the lymphedema caused by CVI to compensate for venous insufficiency: valvular failure of lymphatic vessels by lymphatic overloading.

Therefore, CLI involved to phlebolymphedema is not a simple condition of mechanical insufficiency with low lymph flow due to the defects in the lymph vessels and lymph nodes system nor dynamic insufficiency caused by high lymph flow overwhelming the maximum loadcarrying capacity of a physiologically normal lymphatic system. But this is rather a 'safety valve insufficiency' as the combined effect of increased lymph flow and the reduced drainage capacity in the diseased lymphatic system often as the outcome of advanced post-thrombotic syndrome.

When the lymphatics themselves are damaged following initially enhanced function to compensate for the insufficient venous system, a safety valve insufficiency of lymphatic system occurs with resulting lymphostasis. When the venous stasis exceeds this maximum lymphatic compensatory capacity, the insufficiency becomes 'phlebo- lymphatic', showing characteristics of a major fibrosis due to increased interstitial protein concentration to take degenerative phlebo-lymphatic process resulting in dystrophic ulcers and skin infections, etc.

\section{Etiopathogenesis}

\section{Primary phlebolymphedema}

Such combined condition of the CVI and CLI, named to the 'phlebolymphedema' is well known among combined form of congenital vascular malformation; Klippel-Trenaunay Syndrome (KTS) represents this unique condition of 'primary' PLE according to the hemodynamic evaluation of the pathology. (cf. secondary PLE) $)^{21-24}$.

Among multiple vascular malformation components of the KTS, the most common venous malformation (VM) to cause CVI is 'marginal vein' with venous reflux/hypertension, followed by deep vein dysplasia (e.g. iliac vein agenesis, hypoplastic femoral vein) or defective vein (e.g. web, stenosis, aneurysm, ectasia) with venous outflow obstruction/hypertension. CLI is mostly due to "primary lymphedema by truncular lymphatic malformation (LM) lesion (e.g. lymphatic dysplasia: aplasia, hypoplasia, or hyperplasia). Extratruncular LM (lymphangioma) seldom involved to the CLI ${ }^{25-28}$.

When the marginal vein (MV) as the VM component causes substantial CVI while primary lymphedema by LM causes CLI, these two combined conditions exert synergistic impacts to mutually interdependent and inseparable veno-lymphatic system to make the condition/the limb swelling worse and further to cause an 'indolent ulcer'.

MV is relatively common VM lesion affecting the lower extremity among KTS patients; it often runs along the lateral aspect of the leg usually very superficially beneath the skin with a minimum soft tissue coverage mimicking the ordinary varicose veins. But the MV is NOT a varicose vein! MV is an embryonic vein remnant which failed to involute as a birth defect following the developmental arrest during the vein trunk formation period in the 'later stage' of the embryonic development ${ }^{29-32}$.

MV accompanies a unique condition of congenital absence/lack of venous valves known as the avavulosis/avalvulia to allow a severe reflux resulting in chronic venous hypertension/stasis with subsequent CVI/PTS. And also due to defective/deficient media of the vein wall with lack of smooth muscle layers (cf. varicose vein), this abnormal vessel wall structure carries a high risk of the intravascular thrombosis resulting in VTE (venous thrombo-embolism) in addition to severe CVI and PTS through the rest of life.

\section{Secondary phlebolymphedema}

Secondary PLE develops along the end stage of CVI, as explained previously, as mostly the sequalae of PTS following the DVT, becoming a complicated condition to manage due to newly added condition of local/regional lymphedema. Secondary PLE often shows visibly strained lymphatic system as a victim of abnormal venous condition. This new lymphatic dysfunction becomes a major burdening to the clinical management due to the complexity of local circulation $^{33-36}$

CLI of secondary PLE is generally secondary regional/local lymphedema following steady progress of the local tissue damage (e.g. ulcer) by the CVI/PTS. But, occasionally, clinical/ subclinical condition of primary lymphedema as the cause of CLI accelerates the deterioration of the underlying benign primary venous disorder (e.g. reflux) to result in CVI. 


\section{Table I - Laboratory evaluation for Venous System}

Venous duplex ultrasonography (DUS)

Air plethysmography: functional assessment

CT (computerized tomography) with/without contrast

MRI (magnetic resonance imaging); standard \& MR venography (MRV)

Radioisotope venography

Ascending \& Descending venography

Percutaneous direct puncture phlebography

Volumetry

Whole body blood pool scintigraphy (WBBPS)*

Transarterial lung perfusion scintigraphy (TLPS)* test of choice/mandatory optional

optional

optional

optional

optional

optional

optional

optional

optional

* For the congenital vascular malformation assessment

\section{Table II - Laboratory evaluation for Lymphatic System}

Radionuclide Lymphoscintigraphy

Indocyanine green lymphangiography

MR lymphangiography

Lymphangiography (oil contrast): for the candidate of venolymphatic

reconstructive surgery

Ultrasonographic lymphangiography

CT scan - exclude underlying malignancy

Standard MRI - potentially most useful

Volumetry

Miscellaneous: dermascan, tonometry, ultrasonographic measurement of subcutaneous edema test of choice/mandatory

optional

optional

optional

optional

optional

optional

optional

optional

\section{Diagnostic Assessment in general}

All the chronic venous stasis ulcers resisting to the conventional care are mandated to assess these two closely linked conditions of CVI and CLI together. Simultaneous evaluation of two systems are mandated for any one of two-system assessment. The evaluation for the venous system should be considered as warranted part of chronic lymphedema assessment.

The evaluation of an edema of the limbs should be addressed to exclude or confirm the presence of a systemic cause of edema (cardiac failure, renal failure, Hormonal disturbances, malignant tumors) or a iatrogenic edema related to use of $\mathrm{Ca}$ antagonists, vasodilators, anti-inflammatory drugs. The evaluation of the venous component of the edema should be addressed to evaluate the anatomy of the venous system, the presence, the size and the extension of refluxes both in the deep and superficial veins and the presence of an obstruction which may be congenital or acquired. The lymphatic components may be described as extension, volume of the affected limb and characteristics of the edema which may be pitting or not.

Another words, the lymphatic system assessment as well has to be included to rule out any overlooked/neglected venous lesion to result in the indolent status especially by the 'primary/congenital' origin (e.g. marginal vein/lateral embryonic vein) in addition to a thorough investigation of entire venous system. Therefore, clear understanding on the interrelationship between the venodynamics and lymphodynamics is mandated especially for early aggressive management of PLE. 
The assessment of the extent/severity of the CVI should be based on Duplex ultrasonography (DUS) and may include various plethysmographies in addition to ascending/descending phlebography. For the CLI, the functional status of the lymphatic system should be measured with the lymphoscintigraphy to delineate excessive fluid accumulation in the tissues of the limb or affected lymphatic territories $8,10,11,14,21,22,24,37-40$.

Appropriate appraisal of the CVI and also CLI should start with differential diagnosis between 'primary' PLE of congenital origin and 'secondary' PLE with various backgrounds. (Table I and II)

Non- to less- invasive tests based on the DUS, MRI, and/or CT evaluation is generally sufficient for the MV assessment but occasionally, direct puncture phlebography together with ascending or descending phlebography would be needed as a road map for the surgical intervention in the case of venous malformations.

Morpho-functional studies represent the basis in the evaluation of the hemodynamic of the venous system and duplex scanning is the golden standard. This should be implemented by plethysmographic studies

\section{Clinical Management}

Management of PLE should aim at BOTH conditions of CVI and CLI as an outcome of simultaneous 'dual' outflow system failure so that such combined condition makes the CVI much harder to correct.

Baseline therapy for the PLE is the compression therapy regardless of its etiology. It is a reinforced gradient compression therapy based on the CDT (complex decongestive therapy) to control the CVI and CLI together.

Primary PLE with the reflux of the MV as the cause of CVI should be treated with the resection of the MV as far as the deep vein system could tolerate sudden influx of diverted blood volume. CVI due to deep vein dysplasia occasionally requires more than conservative management when there is a clear evidence for the hemodynamic gain by the bypass surgery of hypoplastic/aplastic iliac/femoral veins to improve indolent ulcers.

The ablation of the MV to relieve CVI is totally depending on the status of deep vein system; it can be done safely only when the deep system is in normal condition. Otherwise, it would accompany a high risk of acute venous stasis to precipitate acute venous gangrene and also cause the deterioration of the CLI by the overloading to the lymphatic system which is already in jeopardy.

Therefore, primary PLE generated by the vascular malformation component of KTS, for example, represents in order to sample quantitative repetitive data on the hemodynamic almost in obstructive syndromes. It can be easily investigated by DUS and a simple Perthes test or by gentle compression by means of the DUS probe.

Evaluation of the venous system with DUS should include full evaluation of hemodynamic status of the MV and the deep vein system simultaneously (e.g. extent and severity of the reflux and outflow resistance) since more than one third of patients with the MV have a defective deep venous system (e.g. hypoplasia of femoral vein, aplasia of iliac vein) as well. Entire length/course of MV, located supra- and sub-fascially, should be visualized together with the perforators.

Lymphatic evaluation is more complex. Morphological evaluation is needed to exclude neoplastic pathology at lymphnode level. Lymph nodes may be enlarged on the basis of chronic inflammation related to the presence of skin ulcers. Morphological evaluation is based on the use of ultrasound or CT scan with contrast medium. Both examinations allow to visualize the edema and they can define the size, the depth. The functional examination of choice is represented by lymphoscintigraphy $8,10,11,14,21,22,24,37-40$.

such complicated interrelationship between venous and lymphatic systems so that KTS is generally mandated for multidisciplinary team management of this combined venous-lymphatic disorder with extremely delicate mutual interdependency between VM and LM.

When the MV presents with an aplastic or hypoplastic iliac- femoral venous system, prophylactic anticoagulation with the weight adjusted LMWH (low-molecular-weight heparin) is generally recommended ${ }^{8,10,11,18,21,22,38,41-44}$.

Secondary PLE with the CVI by PTS should be treated more aggressively to relieve the cause of obstruction/ reflux with various forms of open surgical (e.g. bypass) and endovascular therapy (e.g. angioplasty and stenting). When the CVI is caused by the multilevel DVT sequalae (indolent ulcer), even a minimum correction of the obstruction/stenosis is able to assist tremendous improvement of the efficacy of the compression therapybased conservative management following successful relief of venous hypertension $8,10,11,18,21,22,38,41-44$.

In reality, however, once the lymphatic vessels have been permanently damaged, phlebolymphedema is generally not reversible and the swelling will not disappear although the treatment can improve signs and symptoms. Hence the patients' expectations should be lowered and the patients would need to be aware of that so expectations can be matched. 


\section{Conclusion-1}

Venous and lymphatic systems are inseparable 'dual' outflow systems with mutually complimentary function but based on two entirely different independent fluid dynamics.

- Precise understanding on the critical differences of the rheologic characteristics between venous (low fluctuating flow) and lymphatic (peristaltic flow) system is warranted for the proper management of either one of two inseparable systems.

- Indolent venous stasis ulcers often represent a combined condition of veno-lymphatic edema caused by chronic venous insufficiency (CVI) and chronic lymphatic insufficiency (CLI) of various origins, also known as phlebolymphedema (PLE).

- $\quad$ Primary PLE, caused by vascular malformation component of Klippel-Trenaunay syndrome, is the combined condition of CVI by the marginal vein (MV) and CLI by primary lymphedema.

\section{References}

1) Laredo $J$ and Lee BB. Venous Physiology and Pathophysiology. Chap 2. Pp 23-35. Current Management of Venous Diseases. C.I. Ochoa Chaar (ed.), Springer International Publishing AG 2018

2) O'Donnell TF Jr, et al. Management of venous leg ulcers: clinical practice guidelines of the Society for Vascular Surgery ${ }^{\circledR}$ and the American Venous Forum. J Vasc Surg. 2014;60:3S-59S.

3) Eberhardt RT, Raffetto JD. Chronic venous insufficiency. Circulation. 2014 Jul 22;130(4):333-46. doi: 10.1161/ CIRCULATIONAHA.113.006898.

4) Lee BB, Nicolaides AN, Myers K, Meissner M, Kalodiki E, Allegra $\mathrm{C}$, et al. Venous hemodynamic changes in lower limb venous disease: the UIP consensus according to scientific evidence. Int Angiol. 2016;35(3):236-352.

5) Partsch H, Lee BB: Phlebology and lymphology - A family affair. Editorial. Phlebology 2014, Vol. 29(10) 645-647

6) Lee BB. Phlebolymphedema is the ultimate comorbidity/ outcome of lymphedema. INVITED COMMENTARY for "Lymphedema-Associated Comorbidities and Treatment Gap", J Vasc Surg: Venous and Lym Dis 2019;7:731

7) Bunke N, et al. Phlebolymphedema: usually unrecognized, often poorly treated. Perspect Vasc Surg Endovasc Ther. 2009; 21:65-8.

8) Cavezzi A. DIAGNOSIS AND MANAGEMENT OF SECONDARY PHLEBOLYMPHEDEMA Chap 73. Section - XV - Phlebolymphedema. Pp 913-924. In: LYMPHEDEMA: A Concise Compendium of Theory and Practice. Lee, Byung-Boong; Stanley G.; Bergan J (Eds.), Second Edition, Springer International Publishing AG 2018

9) Levick JR, Michel CC. Microvascular fluid exchange and the revised Starling principle Cardiovasc Res. 2010 Jul 15;87(2):198-210

10) Gianesini S, Menegatti E, Zamboni P. MANAGEMENT OF PHLEBOLYMPHEDEMA ULCER. Chap 74. Section - XV -

\section{Conclusion-2}

- $\quad$ PLE can be managed more effectively when open and/or endovascular therapy is added to the basic compression therapy to control the CVI and CLI together.

- $\quad$ Primary PLE with CVI by the reflux of MV can be treated successfully with MV resection, while CVI by deep vein dysplasia with the conventional compression therapy alone in its majority.

- Secondary PLE with CVI by the postthrombotic syndrome (PTS) can be further improved with correction of the venous outflow obstruction with angioplasty \& stent especially when the DVT sequalae is involved to the multilevels of iliac-femoral-popliteal vein system.

KTS remains the ultimate challenge among various PLEs.

Phlebolymphedema. Pp 913-924. In: LYMPHEDEMA: A Concise Compendium of Theory and Practice. Lee, Byung-Boong; Stanley G.; Bergan J (Eds.), Second Edition, Springer International Publishing AG 2018

11) Piller N. Phlebolymphoedema/chronic venous lymphatic insufficiency: an introduction to strategies for detection, differentiation and treatment. Phlebology. 2009; 24:51-5.

12) Farrow W. Phlebolymphedema-a common under diagnosed and undertreated problem in the wound care clinic. J Am Col Certif Wound Spec. 2010; 2:14-23

13) Mortimer PS. Evaluation of lymphatic function: abnormal lymph drainage in venous disease. Int Angiol 1995;14 (3):32-35

14) Michelini-S, Failla-A, Sterbini-G-P, Micci-A, Santoro-A, Valle-G. Limb phlebolymphoedema: Diagnostic noninvasive approach and therapeutic implications. European Journal of Lymphology and Related Problems 1995 5(20):103-108

15) Eisenhoffer J, Kagal a, Klein T, Johnston MG. Importance of valves and lymphangion contractions in determining pressure gradients in isolated lymphatics exposed to elevations in outflow pressure. Microvascular research. 1995. p. 97-110.

16) Unno N, Nishiyama M, Suzuki M, Tanaka H, Yamamoto $\mathrm{N}$, Sagara D, et al. A novel method of measuring human lymphatic pumping using indocyanine green fluorescence lymphography. J Vasc Surg. Elsevier Inc.; 2010;52(4):946-52.

17) Partsch H, Mostbeck A. Involvement of the lymphatic system in post-thrombotic syndrome Wien Med Wochenschr. 1994;144(10-11):210-3

18) Momin TA and Neville RF. Management of Phlebolymphedema Ulcers. Chapter 66. Section - XVI Phlebolymphedema. Page 557-561, LYMPHEDEMA: A Concise Compendium of Theory and Practice. Lee, Byung-Boong; Bergan, John; Rockson, Stanley G. (Eds.), 1st Edition, Springer-Verlag, London, UK, 2011 
19) Villavicencio JL, Hargens AR, Pikoulicz E. Latest advances in edema. Phlebolymphology 1996;12:9-15.

20) Rockson S.G. The Lymphaticovenous Spectrum of Edema, Lymphatic Research and Biology. 2009, 7(2): 67

21) Lee BB, Laredo J, Neville R, Loose D: Diagnosis and Management of Primary Phlebolymphedema. Chapter 64. Section - XVI - Phlebolymphedema. Page 537-546, LYMPHEDEMA: A Concise Compendium of Theory and Practice. Lee, Byung-Boong; Bergan, John; Rockson, Stanley G. (Eds.), 1st Edition, Springer-Verlag, London, UK, 2011

22) Endicott K, Laredo J, Lee BB. Diagnosis and Management of Primary Phlebolymphedema. Chap 72. Section - XV Phlebolymphedema. Pp 913-924. In: LYMPHEDEMA: A Concise Compendium of Theory and Practice. Lee, Byung-Boong; Stanley G.; Bergan J (Eds.), Second Edition, Springer International Publishing AG 2018

23) Lee BB, Laredo J, Neville R, Mattassi R: Primary lymphedema and Klippel-Trenaunay syndrome. Chapter 52. Section XI - Lymphedema and Congenital Vascular Malformation. Page 427-436, LYMPHEDEMA: A Concise Compendium of Theory and Practice. Lee, Byung-Boong; Bergan, John; Rockson, Stanley G. (Eds.), 1st Edition, Springer-Verlag, London, UK, 2011

24) Lee B.B., Antignani P. L., Baroncelli T. A., Boccardo F. M., Brorson H., Campisi C., Damstra R. J., Flour M., Giannoukas A. D., Laredo J., Liu N. F., Michelini S., Piller N., Rockson S. G., Scuderi A., Szolnoky G., Yamamoto T. IUA-ISVI CONSENSUS FOR DIAGNOSIS GUIDELINE OF CHRONIC LYMPHEDEMA OF THE LIMBS. Int Angiol 2015;34(4):311-332.

25) Lee BB. Marginal vein is not a varicose vein; it is a venous malformation. Veins and Lymphatics (2014); 3:4050: 64-70

26) Lee BB, Laredo J. Hemo-lymphatic malformation: Klippel-Trenaunay Syndrome. Review. Acta Phlebologica 2016 April;17(1):15-22

27) Lee BB. A stepwise daily guide to the KTS. Vasculab Debate. Journal of Theoretical and Applied Vascular Research JTAVR 2016;1(2):33-38

28) Lee BB, Laredo J. Obstructive primary truncular venous malformations- General Overview Chapter 4. Pp 28-36. In: Latest Frontiers of Hemodynamic, Imaging and Treatment of Large Veins. GIAQUINTA A, LEE B.B., SETACCI C, VEROUX P, ZAMBONI P (Eds) 2018

29) Lee BB. Marginal vein is not a simple varicose vein:it is a silent killer! Review. Damar Cer Derg 2013;22(1):4-14.

30) Mattassi R, Vaghi M: Management of the marginal vein: current issues. Phlebology 2007; 22: 283-286

31) Lee BB, Baumgartner I, Berlien P, Bianchini G, Burrows P, Gloviczki P, Huang, Y, Laredo J, Loose DA, Markovic J, Mattassi R, Parsi K, Rabe E, Rosenblatt M, Shortell C, Stillo F, Vaghi M, Villavicencio L, Zamboni P. Diagnosis and Treatment of Venous
Malformations Consensus Document of the International Union of Phlebology (IUP): updated 2013. Int Angiol 2015;34(2): 97-149

32) Lee B. B., Antignani P. L., Baraldini V., Baumgartner I., Berlien P., Blei F., Carrafiello G. P., Grantzow R., Ianniello A., Laredo J., Loose D., Lopez Gutierrez J. C., Markovic J., Mattassi R., Parsi K., Rabe E., Roztocil K., Shortell C., Vaghi M. ISVI-IUA consensus document - diagnostic guidelines on vascular anomalies: vascular malformations and hemangiomas. Int Angiol 2015;34(4):333-374

33) Cavezzi A, Michelini S. Phlebolymphoedema, from diagnosis to therapy Ed. P.R., Bologna 1998, ISBN 88-900300-1-1 .

34) Cavezzi A. Diagnosis and Management of Secondary Phlebolymphedema. Chapter 65. Section - XVI - Phlebolymphedema. Page 547-556, LYMPHEDEMA: A Concise Compendium of Theory and Practice. Lee, Byung-Boong; Bergan, John; Rockson, Stanley G. (Eds.), 1st Edition, Springer-Verlag, London, UK, 2011

35) Starling EH. On the absorption of fluids from the connective tissue spaces. J Physiol. 1896; 19:312-326.

36) Chen WYJ, Rogers A. Recent insight into the causes of chronic leg ulceration in venous diseases and implication on the other types of chronic wounds. Wound Repair Regen. 2007; 15:434-49.

37) Lee BB, Andrade M, Antignani PL, Boccardo F, Bunke N, Campisi C, Damstra R, Flour M, Forner-Cordero J, Gloviczki P, Laredo J, Partsch H, Piller N, Michelini S, Mortimer P, Rabe E, Rockson S, Scuderi A, Szolnoky G, Villavicencio JL. Diagnosis and Treatment of Primary Lymphedema. Consensus Document of the International Union of Phlebology (IUP)-2013. Int Angiol 2013;32(6):541-74

38) Lee BB, Baumgartner I, Berlien P, Bianchini G, Burrows P, Gloviczki P, Huang, Y, Laredo J, Loose DA, Markovic J, Mattassi R, Parsi K, Rabe E, Rosenblatt M, Shortell C, Stillo F, Vaghi M, Villavicencio L, Zamboni P. Diagnosis and Treatment of Venous Malformations Consensus Document of the International Union of Phlebology (IUP): updated 2013. Int Angiol 2015;34(2): 97-149

39) Lee BB, Bergan JJ: New clinical and laboratory staging systems to improve management of chronic lymphedema. Lymphology 2005; 38:122-129.

40) Hampton S. Chronic oedema and lymphedema of the lower limb. Br J Community Nurs. 2010:4S-12S.

41) Kim YW, et al. Haemodynamic and clinical assessment of lateral marginal vein excision in patients with a predominantly venous malformation of the lower extremity. Eur J Vasc Endovasc Surg 2007; $33: 122-127$.

42) Casley-Smith J, Casley-Smith JR. Lymphaticovenous insufficiency and its conservative treatment. Phlebolymphology 1995; 6: 9-13.

43) Litwiniuk M, et al. Chronic inflammation in venous leg ulcer - problems and perspectives. Centr Eur J Immunol. 2009; 34:247-251.

44) Rasmussen JC, et al. Lymphatic transport in patients with chronic venous insufficiency and venous leg ulcers following sequential pneumatic compression. J Vasc Surg Venous Lymphat Disord. 2016; 4:9-17. 